\title{
A Terapia Ocupacional e as novas formas do cuidar em saúde mental*
}

\section{Occupational Therapy and new forms of caring into mental health}

\author{
Mara Cristina Ribeiro¹, Ana Lúcia Machado²
}

RIBEIRO, M. C.; MACHADO, A. L. A Terapia Ocupacional e as novas formas do cuidar em saúde mental. Rev. Ter. Ocup. Univ. São Paulo, v. 19, n. 2, p. 72-75, maio/ago. 2008.

RESUMO: A constituição de redes de atenção psicossocial que trabalhem rumo à implantação de uma ação integrada de base comunitária, sob a diretriz da reabilitação psicossocial vem sendo estimulada. Nesses novos locais de atenção, o profissional de terapia ocupacional deve levar, por meio de sua especificidade, a ampliação do cuidado e a possibilidade de resgate dos direitos de cidadania desses sujeitos. A terapia ocupacional, por ter como ferramenta principal a atividade, que reflete a cotidianidade do sujeito, pode transformar a sua ação junto à sua clientela em promotora de um protagonismo social que historicamente foi arrancado daqueles que foram marcados pela história da psiquiatria. Dessa forma, ela não deve ser apenas um instrumento de intervenção para controle e eliminação do mal-estar psíquico, ela deve contribuir para que a vida coletiva e as existências individuais sejam mais interessantes, abertas e criativa e nós, terapeutas ocupacionais, facilitadores desse processo de transformação, devemos ser incansáveis criadores de possibilidades, inaugurando um cuidado que prioriza a liberdade de criação de todos os sujeitos envolvidos.

DESCRITORES: Terapia ocupacional. Saúde mental. Centros de reabilitação. Serviços de saúde mental. Psiquiatria comunitária.

\footnotetext{
* Trabalho apresentado no VI Congresso Internacional de Saúde Mental e Direitos Humanos em Buenos Aires, Argentina, em 2007.

1. Terapeuta Ocupacional, docente da Faculdade de Terapia Ocupacional e Coordenadora do Curso de Especialização em Saúde Mental da Universidade Estadual de Ciências da Saúde de Alagoas - UNCISAL, mestre em Enfermagem Psiquiátrica - USP e doutoranda em Ciências - USP.

2. Profa. Dra. da EEUSP, docente do Programa Interunidades de Doutoramento da Escola de Enfermagem da USP. E-mail: almachad@, usp.br

Endereço para correspondência: Rua Padre Cícero, 51 - Barra Nova - Marechal Deodoro, Alagoas. CEP 57160-000. E-mail: mararibeiro@usp.br
} 


\section{A TERAPIA OCUPACIONALE AS NOVAS FORMAS DO CUIDAR EM SAÚDE MENTAL}

$\mathrm{O}$ caráter de marginalização e exclusão econômica e social típico da psiquiatria tradicional, imposto aos portadores de transtornos mentais ao longo da história, favoreceu o aparecimento de críticas e de reivindicações que passaram a questionar a legitimidade e a capacidade das instituições e respectivos profissionais para tratar e curar os doentes mentais.

Os critérios técnico-científicos que davam a base de gestão da loucura estabeleceram uma relação social com o louco que o privava de assumir o contrato social que todo cidadão está submetido; assim, a relação instituída foi a relação de tutela, que impossibilitava o indivíduo de participar de uma sociedade como sujeito de direitos e deveres (MANGIA, 2001).

Após a II Guerra Mundial, o modelo psiquiátrico clássico instituído por Pinel, que privilegiava o espaço asilar como local de intervenção na loucura foi revisto e, assim, surgiram propostas e modelos novos, principalmente na Europa e nos Estados Unidos. Esse processo, ao longo dos anos, foi sendo reconhecido e denominado Reforma Psiquiátrica, e posteriormente estendeu-se também para o Brasil.

É preciso apontar que no Brasil tal movimento de questionamento e transformação ocorreu de forma mais tardia, paralelamente ao movimento de abertura política e redemocratização da sociedade brasileira.

Até o final da década de 70, a assistência psiquiátrica brasileira era realizada por meio de internações hospitalares como única forma de tratamento para doentes mentais uma vez que a estrutura manicomial e a oferta de leitos consolidava esse modelo de assistência.

Após sucessivas transformações, a psiquiatria insinuouse em um novo cenário no Brasil: alguns setores da sociedade civil passaram a se mobilizar em favor da luta pelos direitos dos pacientes, abrindo espaço, nos meios universitários, intelectuais e nas próprias instituições psiquiátricas, para novas discussões sobre a loucura. Esse movimento denominou-se Reforma Psiquiátrica Brasileira e se constitui, até os dias atuais, no movimento de garantia das mudanças assistenciais em saúde mental.

A partir de seu surgimento, no campo assistencial, foram criados ao longo dos anos seguintes, em todo o país, novos serviços com propostas de tratamentos diferenciados dos tradicionais, levando em consideração a singularidade e as condições concretas das pessoas que buscam esses serviços.

Nessas novas propostas, um dos grandes princípios a ser considerado é a questão da cidadania. Também a loucura passa a ser percebida em sua complexidade e não mais pela objetivação da psiquiatria. Ampliam-se os movimentos sociais, como as associações de familiares e usuários, além de cooperativas e eventos com o objetivo de possibilitar a construção de novas formas de convivência (RIBEIRO, 2005).

No contexto da Terapia Ocupacional aplicada aos sujeitos com a experiência do sofrimento psíquico, a primeira grande alteração deu-se com a mudança do perfil de seu cliente hospitalizado, pois, por meio da Previdência Social, o Estado passou a subsidiar a iniciativa privada na assistência psiquiátrica, ampliando seus serviços para a classe trabalhadora e seus dependentes, com isso estrutura-se uma atenção marcada pela alta rotatividade, o que passa a inviabilizar a laborterapia clássica.

Com os novos rumos que a psiquiatria foi tomando, inclusive o uso da nova denominação "saúde mental", surgiram outras orientações que caracterizaram o panorama da terapia ocupacional psiquiátrica brasileira contemporânea.

Entre elas podemos destacar a terapia ocupacional junguiana, dirigida por Nise da Silveira; a socioterapia, desenvolvida por Luis Cerqueira; a terapia ocupacional psicodinâmica, impulsionada por Maria José Benetton; e os projetos de transformação institucional, que ocorreram em várias partes do país.

É importante pontuar que, dentro desse contexto histórico, toda a Saúde passava por um processo de reconstrução. Vislumbrava-se uma nova concepção sobre o processo saúde-doença, gerando modelos de atenção nos quais as respostas aos problemas de saúde não fossem encontradas unicamente nos serviços médicos, e que o próprio conceito de Saúde não fosse definido como ausência de doença.

Dessa forma, atualmente vem sendo estimulada a constituição de redes de atenção psicossocial que trabalhem rumo à implantação de uma rede integrada de base comunitária, com ofertas complexas de atenção médico-social, sob a diretriz da reabilitação psicossocial.

Esse movimento é marcado pela construção de uma nova postura ética em relação aos indivíduos acometidos por transtornos mentais. O sujeito não mais deve ser visto como portador de uma doença que precisa ser controlada, mas sim como pessoa que, devido às suas diferenças, necessita de locais e pessoas que o ajudem a garantir sua cidadania, a sua qualidade de vida, enfim, as suas trocas sociais e afetivas (RIBEIRO, 2005)

Nesses novos locais de atenção, o profissional de terapia ocupacional deve levar, por meio de sua especificidade, a ampliação do cuidado e a possibilidade de resgate dos direitos de cidadania desses sujeitos.

A terapia ocupacional, por ter como ferramenta princi- 
pal a atividade, que reflete a cotidianidade do sujeito, pode transformar a sua ação junto à sua clientela em promotora de um protagonismo social que historicamente foi arrancado daqueles que foram marcados pela história da psiquiatria.

Para tanto é preciso mudar o olhar sobre a atividade, não mais trabalhar com a atividade como uma abstração esvaziada de sentido concreto para o indivíduo, mas unir sua função interpretativa, que se dá através da dimensão inconsciente absorvida da psicologia, com seu conceito de historicidade, nutrido pela dimensão sócio-política e cultural enquanto instrumento para a emancipação (BARROS et al., 2002).

Assim, o terapeuta ocupacional deixa de ocupar o lugar de balizador do processo da atenção e permite que esse lugar seja compartilhado com outros agentes do processo, onde a atividade passa a ser percebida, vivida e interpretada por cada um de seus atores (a pessoa, o terapeuta ocupacional, a família, a cultura e os valores buscados).

O empréstimo de seu poder contratual para a efetivação e enriquecimento das trocas sociais na população assistida por esse profissional deve acontecer não apenas dentro dos alicerces institucionais, é preciso conhecer o território onde essas pessoas vivem, desejam, sofrem... O lugar da Terapia Ocupacional, no novo modelo de atenção em saúde mental, comprometido com a ética, com o direito, com a cidadania, é onde as populações com carência desses conceitos e, por conseguinte, dessas práticas, estão.

Os profissionais de terapia ocupacional que estão inseridos na rede de atenção à saúde mental, e aqueles que serão incluídos neste sistema de atendimento, devem estar cientes de que as transformações nos modelos de atenção em saúde mental vão para além da implantação e ampliação das redes de serviço. Elas conduzem a um outro saber que exige flexibilidade nas ações e nos papéis dos diversos profissionais, e pede uma mudança individual e coletiva de todos os envolvidos no processo da reabilitação psicossocial.

Para garantirmos uma ação comprometida com o processo de reabilitação psicossocial e exercício da cidadania é preciso, primeiramente, ultrapassarmos o equívoco do conceito de complexidade como sinônimo de complicação. A complexidade deve ser considerada como desafio e incitamento para pensar, pois representa o incompleto do conhecimento, do conhecimento multidimensional (MORIN, 1998)

A complexidade identificada na concepção da atenção psicossocial sugere a existência de contradições, indeterminações, probabilidades, dificuldades e ligações que contradizem o pensamento simplificador (PEREIRA, 2003).

Daí a complexidade ser um conceito fundamental nesse processo, pois força-nos a repensar constantemente em nos- sos papéis, pondo em cena e problematizando o lugar que o cuidado em saúde mental deve estar: um lugar de conflito, de confronto e contradição.

A Terapia Ocupacional não deve ser apenas um instrumento de intervenção para controle e eliminação do malestar psíquico, ela deve contribuir para que a vida coletiva e as existências individuais sejam mais interessantes, abertas e criativa e nós, terapeutas ocupacionais, facilitadores desse processo de transformação, devemos ser incansáveis criadores de possibilidades.

Trabalhar em serviços que possibilitam novas práticas incita uma nova compreensão, requer movimentos internos que conduzem para a intersubjetividade e provoca desejos de descoberta; dessa forma, possibilita ao profissional transformar a si mesmo enquanto transforma suas ações (PEREIRA, 2003)

A nova lógica de funcionamento da assistência no campo da saúde mental traz para seus profissionais novos desafios: é preciso um posicionamento político para o enfrentamento da exclusão não apenas dos usuários dos serviços, mas da própria saúde mental, que fica isolada e muitas vezes esquecida pelos órgãos que estabelecem as diretrizes das práticas de construção desses serviços.

Portanto é preciso unir forças. Um bom exemplo disso é a compreensão da necessidade da presença de um programa de ensino dentro dos serviços de atenção psicossocial, pois este colabora tanto para a reciclagem dos profissionais da instituição quanto na formação dos novos profissionais que logo entrarão no campo de trabalho.

Essas parcerias têm importante papel no processo de reformulação constante da assistência em saúde mental, garantindo o questionamento contínuo das práticas, a aproximação do campo teórico, a não cristalização de posturas e, através desse contato, propiciam o aparecimento de idéias inovadoras que podem resultar em experiências que agregam o campo teórico ao prático.

Para Bezerra Júnior (2004) essa parceria enriquece tanto a universidade quanto a rede, resultando na melhora da formação dos alunos, estimulando os profissionais, beneficiando a assistência, garantindo, dessa forma, a permanência de discussão constante que resiste àquela conhecida acomodação inercial de qualquer instituição.

É possível pensar, a partir dessa detecção, que o processo contínuo de Reforma Psiquiátrica, bem como o entendimento do que é e como exercer a atenção psicossocial, poderia ser facilitado se tivéssemos, por parte das instituições universitárias, um enfoque comprometido com esses conceitos na formação dos novos profissionais. Outra conquista possível dentro dessa proposta seria uma maior produção de conhecimento, de experiência teórica, minimizando construções práticas descoladas do saber. 
Para garantir práticas reais de emancipação e autonomia, resultando em um incremento na qualidade de vida dos usuários dos serviços de saúde mental, não devemos nos esquivar do nosso papel enquanto profissionais operadores da reabilitação e do papel da instituição na qual estamos inseridos.

Para tanto, é necessário o entendimento do novo campo de ação em saúde mental, que percorre as subjetividades do usuários dos serviços, passa por todos os atores envolvidos no processo do cuidar e estende-se à família e à comunidade onde o sujeito deve estar e ser inserido.

Como afirma Mangia (2002), essa nova forma de responsabilizar-se e produzir projetos terapêuticos singulares deve, vislumbrar um descentramento da ação, num movimento que prioriza ações extra institucionais e potencializa recursos presentes no contexto dos sujeitos em seus territórios existenciais concretos e simbólicos.

É preciso compreender que as práticas reabilitadoras devem se encontrar no exercício dos direitos sociais e, para isso, devem poder sair do discurso técnico para fazerem sentido, para se aproximarem da realidade social, com seus conflitos, contradições, sensos e contra-sensos, ou seja, a terapia ocupacional, para que possa constituir-se efetivamente como promotora da reabilitação psicossocial, deve também estar nas ruas, nos mercados, nas praças, na vida... inaugurando um cuidado que prioriza a liberdade de criação de todos os sujeitos envolvidos.

RIBEIRO, M. C.; MACHADO, A. L. Occupational Terapy and new forms of caring into mental health. Rev. Ter. Ocup. Univ. São Paulo, v.19, n. 2, p. 72-75, maio/ago. 2008.

\begin{abstract}
There's lately been an encouragement for the constitution of nets of psychosocial attention that worked toward the introduction of an integrated action within a communal basis, under the psychosocial rehabilitation guidelines. In those new sites of attention, the occupational therapy professional must take, according to its specificity, the enlarging of the care and also the possibility of retrieving the citizenship rights of the subjects. As the main tool in occupational therapy is the activity which reflects the subject's day-by-day, it may transform the action by promoting back a social protagonism from whom it was torn: those marked by history of psychiatry. Therefore, the occupational therapy should not be barely an instrument of intervention for controlling and eliminating psychic malady. Otherwise it should contribute for the development of an individual and collective life and existence more interesting, more open and also more creative. We, occupational therapists and facilitators of this transformation process, should be fatigueless achievers of possibilities, inaugurating a caution which priority may be the liberty of creation of all the subjects involved.
\end{abstract}

KEY WORDS: Occupational therapy. Menthal health. Rehabilitation centers. Mental health services. Community psychiatry.

\title{
REFERÊNCIAS
}

BARROS, D. D.; GHIRARD, M. I. G.; LOPES, R. E. Terapia ocupacional social. Rev. Ter. Ocup. Univ. São Paulo, v. 13, n. 3, p. 95-103, set./dez. 2002.

BEZERRA JÚNIOR, B. O cuidado nos CAPS: os novos desafios. In: ALBUQUERQUE, P.; LIBÉRIO, M. (orgs.). O cuidado em saúde mental: ética, clínica e política. Rio de Janeiro: Coordenação de Saúde Mental da Secretaria Municipal de Saúde do Rio de Janeiro, 2004. p. 3-11.

MANGIA, E. Contribuições da abordagem canadense "prática de terapia ocupacional centrada no cliente" e dos autores da desinstitucionalização italiana para a terapia ocupacional em saúde mental. Rev. Ter. Ocup. Univ. São Paulo v. 13, n. 3, p. $127-134$, set./dez. 2002 .

MANGIA, E. F.; NICÁCIO, F. Terapia ocupacional em saúde mental: tendências principais e desafios contemporâneos. In: PRADO DE CARLO, M.M.R.; BARTALOTTI, C.C. (orgs.). Terapia ocupacional no Brasil: fundamentos e perspectivas. São Paulo: Plexus Editora, 2001.

MORIN, E. Ciência com consciência. $2^{\mathrm{a}}$ ed. Rio de Janeiro: Bertrand Brasil, 1998.

PEREIRA, M. A. O. A reabilitação psicossocial no atendimento em saúde mental: estratégias em construção.Ribeirão Preto, 2003. Tese (Livre docência) - Escola de Enfermagem de Ribeirão Preto/ Universidade de São Paulo.

RIBEIRO, M. C. A reabilitação psicossocial num CAPS: concepção dos profissionais. São Paulo, 2005. Dissertação (mestrado) - Escola de Enfermagem da Universidade de São Paulo. 